ISSN: 0213-2060

DOI: https://doi.org/10.14201/shhme2020381221238

\title{
LAS ORDENANZAS GENERALES DE ÁVILA DE 1487. EL CÓDICE ORIGINAL. CONTENIDOS RECUPERADOS PARA UNA EDICIÓN DEL TEXTO ÍNTEGRO
}

\author{
The Ordenanzas generales de Ávila of 1487. The Original Codex. Recovered Contents \\ for an Edition of the Complete Text \\ Miguel CARABIAS ORGAZ \\ Sociedad de Estudios Medievales y Renacentistas. Facultad de Filología. Universidad de Salamanca. Plaza de \\ Anaya, s/n.E-37008 SALAMANCA. C. e.: miguelcarabias@usal.es
}

Recibido: 2019-02-21

Revisado: 2019-10-30

Aceptado: 2020-05-04

RESUMEN: Damos a conocer un códice de finales del siglo xv que contiene parcialmente el texto de las Ordenanzas generales de Ávila aprobadas en 1487. Se trata de un manuscrito que, pese a no haberse conservado completo, ofrece diversos atractivos, el principal de los cuales es una serie de disposiciones totalmente desconocidas -hasta hoy se creían perdidas-, que permitirán recuperar por completo esta obra. Presentamos aquí una descripción del manuscrito y de su contenido textual. A continuación, esbozamos un análisis comparativo de los distintos testimonios y finalmente trazamos las pautas para una edición del texto íntegro.

Palabras clave: Ordenanzas locales; Ávila; Concejo medieval; Baja Edad Media.

ABSTRACT: We present a codex of the late fifteenth Century that partially contains the text of the Ordenanzas generales de Avila approved in 1487. It is a manuscript that, despite not having been completely preserved, offers several attractions: the main one of them is a series of completely unknown dispositions, which will allow to fully recover these Ordenanzas. We present here a description of the manuscript and its textual content. Next, we outline a comparative analysis of the different testimonies and finally we draw the guidelines for an edition of the full text.

Keywords: Municipal ordinances; Ávila; Medieval Council; Late Middle Ages. 
SUMARIO: 0 Ordenanzas medievales de Ávila y su tierra. 1 Testimonios manuscritos y ediciones modernas. 2 Descripción codicológica y paleográfica. 3 Alcance y contenido del manuscrito. 4 Pautas para una edición de las Ordenanzas generales de 1487. 5 Anexo: Correspondencias entre los distintos testimonios. 6 Referencias bibliográficas.

\section{Ordenanzas medievales de Ávila y SU TIERRA}

Parece indudable que el origen de las ordenanzas municipales en la Corona de Castilla, durante la Baja Edad Media, está estrechamente ligado a la decadencia de los fueros ${ }^{1}$, cuyos contenidos resultaban ya inefectivos, de manera que la autoridad municipal se había visto precisada a proponer una nueva forma de regular la vida en las ciudades y sus tierras. Estas ordenanzas representaron, pues, la última etapa en el desarrollo del derecho local durante el periodo medieval ${ }^{2}$.

Fueron las ordenanzas municipales el resultado de resoluciones adoptadas en el concejo, el cual ostentaba la potestad normativa; es decir, que pueden considerarse sobre todo una acción de gobierno, pues mediante ellas se encauzaban y afianzaban las estrategias del poder urbano ${ }^{3}$. No obstante, la Corona tuvo una importante capacidad de intervención, que tras las cortes de Alcalá de 1348 supuso la aparición de corregidores y regidores muy vinculados al poder real. El intervencionismo regio se consolidó durante el reinado de los Reyes Católicos, con lo que se terminaron limitando de manera considerable las competencias legislativas de los municipios, circunscritas al ámbito administrativo y económico ${ }^{4}$. En contrapartida, las ciudades verán afianzada su autonomía a la hora de legislar en dichos ámbitos. En la Corona de Castilla, las ordenanzas municipales se configuraron tras un proceso de compilación, particularmente intenso entre finales del siglo XIV y comienzos del XVI, y permitieron unificar y homogeneizar la actuación política, fortaleciendo el poder de los concejos $^{5}$; un ejemplo paradigmático lo tenemos en la ciudad de Ávila y su tierra.

No será necesario insistir en la especial importancia que tienen las primeras ordenanzas municipales castellanas, principalmente como fuentes históricas que permiten

1 Porras Arboledas, Pedro Andrés. «La práctica de la policía en Castilla a través de los fueros, ordenanzas y bandos de buen gobierno durante los siglos XIII al XVI». En CaUchies, Jean-Marie y Bousmar, Éric (dirs.). "Faire bans, edictz et statuz»: Légiférer dans la ville médiévale. Sources, objets et acteurs de l'activité législative communale en Occident, ca. 1200-1500. Actes du colloque international tenu à Bruxelles les 17-20 novembre 1999. Bruxelles: Publications des Facultés Universitaires Saint-Louis, 2001, pp. 577-586.

2 Ladero Quesada, Manuel F. Las ciudades de la Corona de Castilla en la Baja Edad Media (siglos XIII al XV). Madrid: Arco Libros, 1996.

3 Olmos Herguedas, Emilio. "El poder urbano y sus estrategias para influir sobre el territorio. Aproximación metodológica desde las ordenanzas concejiles castellanas». En Arízaga Bolumburu, Beatriz y Solórzano Telechea, Jesús Ángel (eds.). La ciudad medievaly su influencia territorial. Logroño: Instituto de Estudios Riojanos, 2007, pp. 493-517.

4 Porras Arboledas, Pedro Andrés. «Las ordenanzas municipales. Algunas propuestas para su estudio y un ejemplo». Espacio, Tiempo y Forma. Serie III, Historia Medieval, 1994, vol. 7, pp. 49-64.

5 Olmos Herguedas, Emilio. "Les ordonnances municipales dans la Couronne de Castille au Bas Moyen Âge». European Review of History-Revue Européenne d'Historie, 1994, vol. 1, n. o 1, pp. 101-104. 
conocer la organización y funcionamiento de los concejos en la Baja Edad Media ${ }^{6}$, también como espejo de la sociedad e instituciones de la Castilla tardomedieval, e incluso por su valor lingüístico. Se hace, pues, indispensable el trabajo filológico que permita recuperar y fijar los textos como punto de partida para cualquier estudio: el del historiador especializado en la Edad Media, el del historiador del Derecho o el del historiador de la Lengua.

Particular interés entrañan las Ordenanzas generales de Ávila de 1487, que se han considerado la primera gran recopilación castellana, modélica para el estudio de los gobiernos urbanos del final de la Edad Media ${ }^{7}$, y que han sido descritas como el texto más extenso y completo de los que se conocen en este periodo ${ }^{8}$. Tal como ya explicó José María Monsalvo9, las Ordenanzas de 1487 son una amplia recopilación y reelaboración normativa que el concejo abulense quiso institucionalizar y consolidar como fuente de derecho local. El germen de este corpus normativo se remonta a la mitad del siglo xIV, pues es fruto de un proceso de fusión y ampliación en que convergen dos grandes grupos de disposiciones: por un lado, las conocidas como "ordenanzas de panes y viñas» y otras materias del ámbito agropastoril, de hacia 1346; por otro lado, las denominadas "ordenanzas de fieles», conjunto de disposiciones destinadas a la reglamentación del mercado, abastecimientos, ventas, etc.

Reunido el concejo el 8 de octubre de 1485, constató en las antiguas ordenanzas «muchas diferençias e escuridades, por ser como eran fechas grandes tienpos avía, porque los tiempos en que pareçían ser fechas las dichas ordenanças e los tienpos que agora corrían eran ya de otra calidad»; de manera que fue constituida una comisión a la que se encomendaría la labor de «enmendar e corregir las dichas ordenanças antiguamente fechas, o ordenar e fazer otras ordenanças de nuevo conçernientes, perteneçientes segund la calidad y tienpos que agora corren». Se emprendía entonces el trabajo de recopilación y redacción que daría como resultado un texto nuevo. Inicialmente, «asinaron lugar donde se junten a fazer lo susodicho en Cardeñossa, aldea de la dicha çibdat, para ser allí el día de sant Andrés primero que viene». Un año y medio después, en febrero de 1487, la comisión se reunía de nuevo para sustituir a algunos de los diputados que formaban parte de ella, estableciendo también un nuevo lugar de reunión: "para fazer e hordenar las dichas ordenanças de nuevo o enmendar las ordenanças antiguas del dicho conçejo,

6 Para una visión de conjunto sobre las ordenanzas locales en la Corona de Castilla, siguen siendo de utilidad: Ladero Quesada, Miguel Ángel y Galán Parra, Isabel. «Las ordenanzas locales en la Corona de Castilla como fuente histórica y tema de investigación (siglos XIII al XVIII)». Anales de la Universidad de Alicante. Historia Medieval, 1982, vol. 1, pp. 221-243; y Ladero Quesada, Miguel Ángel. "Las ordenanzas locales. Siglos XIII-XviII». En la España Medieval, 1998, vol. 21, pp. 293-337.

Martín Carramolino, Juan. Historia de Avila, su provincia y obispado. Madrid: Librería Española, 1873, vol. III, p. 81. Belmonte Díaz, José. La ciudad de Ávila. Estudio histórico. Ávila: Caja de Ahorros de Ávila, 1987, p. 163. Álvarez Álvarez, César. «Los archivos municipales: fuentes básicas para el estudio de los derechos locales en la Corona de Castilla». Revista de Historia Jerónimo Zurita, 2004, vol. 78-79, p. 64.

8 Corral García, Esteban. "Algunas manifestaciones de la potestad de ordenanza en Castilla y León». Boletín de la Institución Fernán González, 1984, vol. 202, p. 50.

9 Monsalvo Antón, José María. Ordenanzas medievales de Ávila y su Tierra. Ávila: Institución Gran Duque de Alba, 1990, p. 11. 
LAS ORDENANZAS GENERALES DE AVILA DE 1487. EL CÓDICE ORIGINAL.

CONTENIDOS RECUPERADOS PARA UNA EDICIÓN DEL TEXTO ÍNTEGRO MIGUEL CARABIAS ORGAZ

porque mejor lo pudiesen fazer, dixeron que les elegían e eligieron el monesterio de señor Sant Françisco».

En la elaboración del nuevo ordenamiento intervinieron todos los «estados» de la ciudad de Ávila y de su tierra: regidores, caballeros, procuradores de la tierra, representantes de los pecheros y del estado eclesiástico ${ }^{10}$. Llama la atención, sobre todo, la intervención del clero, que no era en absoluto habitual ${ }^{11}$. También es relevante el hecho de que el estamento de los caballeros tuviera voz de forma independiente y diferenciada con respecto a los regidores, indicio de que el estamento privilegiado se había incorporado a la toma de decisiones en el gobierno de la ciudad, pese a que todavía su papel resultara subsidiario en comparación con el de dichos regidores ${ }^{12}$.

El texto de las Ordenanzas se aprobaría, finalmente, el 16 de marzo de 1487. Los diputados y procuradores hicieron juramento, reunidos en el convento de San Francisco, y posteriormente:

se fueron a la plaça de Mercado Chico e, estando a los luzillos de la cabeçera de la yglesia de señor Sant Juan, e estando ý otra mucha gente de la dicha çibdat, para fazer la dicha publicaçión de las dichas ordenanças, mandaron repicar e repicaron todas las canpanas de la yglesia mayor de Sant Salvador, e ansý mesmo las canpanas de la dicha yglesia de Sant Juan, e tañendo tronpetas e atabales e tanborinos en presençia de nos los dichos Fernand Sanches de Pareja e Juan Rodrigues Daça, escrivanos públicos sobredichos, e de los testigos de yuso escritos, el dicho señor Alfonso Portocarrero, corregidor, e los dichos seńores dyputados e el deán e canónigos e procuradores de la dicha çibdad, mandaron publicar e se publicaron las dichas ordenanças, pregonándolas a altas e intilegibles bozes Pero Gomes, pregonero público de la dicha çibdat.

Es destacable que no se hiciera alusión alguna a intervención o confirmación regia, más allá de la presencia del corregidor.

En cuanto al contenido de estas Ordenanzas generales, es ciertamente amplio y variado. Siguiendo la clasificación temática propuesta por Corral ${ }^{13}$, podemos reconocer como principales ámbitos: organización y funcionamiento del concejo, policía urbana, policía rural, abastos y precios, actividad económica y comercial, hacienda. Para un análisis exhaustivo de estos contenidos y su distribución en leyes u ordenanzas, se podrá consultar el estudio de Ajo González ${ }^{14}$.

10 Para más detalles acerca de la participación de los diversos «estados» en la elaboración de las ordenanzas, véase el estudio de Gautier Dalché, Jean. «Les processus de décision dans un gouvernement urbain selon les Ordonnances d’Ávila (1487)». En la España Medieval, 1985, vol. 6, pp. 507-520.

11 Corral García, "Algunas manifestaciones», p. 51.

12 Monsalvo Antón, José María. «Gobierno municipal, poderes urbanos y toma de decisiones en los concejos castellanos bajomedievales (consideraciones a partir de concejos salmantinos y abulenses)». En Las sociedades urbanas en la España medieval: XXIX Semana de Estudios Medievales. Estella: Gobierno de Navarra, 2003, p. 474.

13 Corral García, Esteban. Ordenanzas de los concejos castellanos: formación, contenido y manifestaciones (s. XIII-XVIII). Burgos: E. Corral, 1988.

14 Ajo González de Rapariegos, Cándido M. ${ }^{a}$. Historia de Ávila y de toda su tierra, de sus hombres y sus instituciones, por toda su geografía provincial y diocesana. Tomo XII. Ávila: Institución Alfonso de Madrigal, 
A juicio de Corral, el ordenamiento abulense destaca sobre otros, principalmente, por su gran extensión, con un contenido impropio de aquella época, pues desarrolla de forma pormenorizada ciertos aspectos como las funciones y derechos de los fieles; también por la amplia participación de todos los «estados» en el proceso de elaboración; por su marcado carácter económico, con una abundante normativa de tipo fiscal y extensas regulaciones sobre las rentas y derechos del concejo, así como legislación sobre los derechos de ciertos profesionales y oficiales -escribanos, alguaciles, fieles-; finalmente, por el carácter concordado de ciertas disposiciones, que surgen o se incorporan por vía de concordia o pacto, como sucede en la ordenanza de los escribanos o en la referida al abastecimiento de carne ${ }^{15}$.

\section{TESTIMONIOS MANUSCRITOS Y EDICIONES MODERNAS}

El texto de las Ordenanzas de 1487 ha sido conocido hasta ahora, principalmente, a través de dos testimonios más o menos contemporáneos, ambos incompletos y que presentan importantes divergencias entre sí. Se conserva también un testimonio del siglo XVIII, pero apenas aporta novedades. Además, sabemos que exisitió otra copia del año 1793, desgraciadamente hoy perdida, que fue consultada por Martín Carramolino en la segunda mitad del siglo xIX, y no descartamos que pudiera haber otras de las que ni siquiera ha quedado constancia.

Fue editada esta obra por primera vez hace más de cien años por el marqués de Foronda, quien la publicó en el Boletín de la Real Academia de la Historia y después en un volumen independiente también bajo el amparo de la Academia ${ }^{16}$. Más recientemente, Monsalvo llevó a cabo una edición que mejoraba la anterior, subsanando algunos errores y poniendo las Ordenanzas generales en su contexto normativo al publicarlas junto con otras disposiciones abulenses del periodo medieval ${ }^{17}$, aunque no pudo ofrecer el texto íntegro por falta de testimonios.

Finalmente, nosotros añadimos un testimonio hasta ahora desconocido $(O)$, cuya singularidad lo hace de excepcional importancia: como adelantábamos, presenta contenidos que no se encuentran en los otros manuscritos y que permiten abordar una edición del texto íntegro.

He aquí la relación completa y actualizada de los testimonios que transmiten -todos ellos parcialmente- las Ordenanzas generales de 1487:

el Tostado-Centro de Estudios e Investigaciones Ascético-místicos, Histórico-bíblicos y Literarios, 1994, pp. 183-194.

15 Corral García, «Algunas manifestaciones», p. 54.

16 Foronda, Marqués de. "Las ordenanzas de Ávila». Boletín de la Real Academia de la Historia, 1917-1918, vol. 71, pp. 381-425 y 463-520; vol. 72, pp. 25-47, 225-254 y 310-326; ForondA, Marqués de. Las ordenanzas de Ávila (manuscrito de 1485 y su copia, en acta notarial, de 1771) publicadas en el Boletín de la Real Academia de la Historia. Madrid: Real Academia de la Historia, 1918.

17 Monsalvo Antón, Ordenanzas medievales de Ávila. 
O: Ms. Salamanca, biblioteca particular. Copiado sobre papel. Mútilo. Foliación moderna hasta el 83. Faltan los fols. 6-29, 31, 77 y desde el 83. Queda descrito con mayor detalle en el epígrafe siguiente.

A: Ms. Ávila, Archivo Municipal de Ávila ${ }^{18}$, Fondos Especiales, Lo 348 (olim. Archivo Histórico Provincial de Ávila, Sección Ayuntamiento, Fondos Especiales). Copiado sobre pergamino muy fino o vitela, con encuadernación de piel posterior. El libro está cuidadosamente restaurado. Dimensiones: 204x280 mm. Letra cortesana. Decoración: iniciales trazadas en rojo, azul y morado, con rasgueo, algunas de grandes dimensiones; calderones rojos y azules. Foliación con números arábigos que llega hasta el 83, signaturas al vuelto de los fols. con números romanos. Mútilo: perdió los fols. 52-63, 72, 73, 78 y desde el 83.

B: Ms. Ávila, Archivo Municipal de Ávila, Hist. 2/6. Copiado sobre papel con filigranas -dibujo de una mano bajo flor de seis pétalos-. Aún tiene la encuadernación original, de piel gofrada sobre tabla, con cierres. El códice se encuentra en mal estado de conservación. Dimensiones: 215×290 mm. Letra cortesana. Decoración: iniciales en rojo, azul y oro, solo hasta el fol. 11. Foliación con números arábigos que llega hasta el 61. Mútilo: perdió los fols. 17-27 y 46-50. Los fols. 55-61 están en blanco.

C: Ms. Ávila, Archivo Municipal de Ávila, Hist. 2/7. Copia sobre papel fechada en 4 de septiembre de 1761. Legajo cosido, sin cubiertas. Contiene 84 hojas, sin foliar. Rúbricas al margen. Reproduce el texto de $B$, aunque con algunos errores.

$D$ : Martín Carramolino estudió, hacia 1873, un manuscrito hoy perdido, copia del siglo xviII, que él describía como «una limpia y esmerada copia legal, dada en 31 de octubre de 1793 por el escribano Ramón Vidal Thenorio»" ${ }^{19}$. A nosotros solo han llegado indirectamente algunos pasajes que transcribió el mencionado historiador ${ }^{20}$.

\section{DesCripCión CODICOLÓGICA Y PALEOGRÁFICA}

El que damos a conocer es un códice copiado a finales del siglo xv, entre 1487 y 1490, constituido por 59 folios más tres hojas sueltas que se añadieron hacia la primera mitad del siglo Xvi. Las dimensiones del folio son $303 \times 218 \mathrm{~mm}$, la caja de escritura oscila entre 110-120x160-170 mm, el número de líneas por plana oscila entre 24 y 30 . El volumen no conserva su encuadernación original y se ha visto deteriorado, con pérdida

18 Conste mi agradecimiento a M.a Sonsoles Guillén Ruiz-Ayúcar y a todo el personal del archivo, que tan amablemente me facilitó la consulta de los tres documentos aquí descritos.

19 Martín Carramolino, Historia de Ávila, p. 75.

20 Aquella copia seguramente contenía el texto completo, con sus 117 ordenanzas, más cuatro añadidos: las rectificaciones a la ordenanza de los escribanos, la ordenanza de los tejeros y olleros, la ordenanza sobre la compra de cabritos, aclaración sobre la ordenanza de los paños, y unas "condiciones de los guardas de los pinares». Martín Carramolino analizó el contenido de varias disposiciones, incluyendo alguna de las hasta ahora inéditas, y recogió en un apéndice todos los títulos o epígrafes, con lo que tenemos una relación completa de las 117 disposiciones y podemos conocer el orden en que figuraban. Martín Carramolino, Historia de Ávila, pp. 80 y 449-455. 
de varios folios; fue reencuadernado con posterioridad, aunque mantiene la composición original de los cuadernos supervivientes, algunos de los cuales tienen signaturas. De la colación de los cuadernos se deduce que la estructura del volumen pudo ser la siguiente:

1. Ternión, no sign., 1 h. en blanco + fols. 1-5.

2. [Senión perdido, fols. 6-17].

3. [Senión perdido, fols. 18-29].

4. Senión, sign. I-XII, fols. 30-41 (falta el fol. 31).

5. Senión, sign. I-XII, fols. $42-53$ (el fol. 47 está rasgado, con leve pérdida de texto).

6. Senión, sign. I-VI, fols. 54-65.

7. Senión, sign. I-VI, fols. 66-77 (falta el fol. 77).

8. Cuaternión, no sign., fols. 78-85 (el fol. 81 está rasgado, con pérdida de texto, y faltan los fols. 84 y 85).

9. Sueltas, $3 \mathrm{~h}$.

El papel utilizado es grueso, de buena calidad, con filigranas que representan una mano y una flor de seis pétalos -similar a Briquet 11159-. Se reconoce bien el pautado, que fue trazado para la justificación o caja de escritura mediante dos rayas verticales y dos horizontales. También se observan pinchazos de guía. La foliación es moderna, de números arábigos, ańadida a lapicero: ff. [1] h. en blanco + 1-5 + 30 + 32-76 + 78-83. Como queda dicho, se hizo uso de signaturas en la composición de algunos cuadernos (fig. 1): en los dos primeros seniones conservados, signatura por folios; en los dos siguientes, por bifolios; en todos los casos, mediante números romanos consecutivos, al recto del folio, situándose en el ángulo inferior derecho.

En cuanto a la tipología escrituraria, se emplea letra cortesana, aunque alejada de las variantes más cursivas. Se trazaron iniciales de mediano tamaño -entre 3 y 4 líneasdecoradas con tinta roja, azul y morada, alternando con rasgueo de color contrastante. En el interior de algunos párrafos, las subdivisiones se indican mediante calderones rojos y azules.

El manuscrito fue copiado por dos manos diferentes. Si leemos la aprobación final de las Ordenanzas, el escribano Fernán Sánchez de Pareja nos explica: «las escreví con mi propia mano de mi letra fasta las sesenta y dos leyes, y lo otro fiz escrevir». Precisamente, aquellos cuadernos que contenían las ordenanzas 1-62 son los que se han perdido, aunque parece difícil saber si se trata solo de una coincidencia. Además, el propio escribano revisa todo e introduce las correcciones pertinentes, añade los epígrafes o títulos y la fe de erratas al final. También se observan algunas anotaciones marginales, de diferentes manos y épocas.

El íncipit (fol. 1r), en transcripción paleográfica: «Enla noble çibdat de aujla ocho dias del $\mid$ mes de otubre año del nafçimjento de núo | fenor ihu xṕo de mjll $\tau$ quatroçientos $\mid \tau$ ochenta $\tau$ çinco Años eftando el con | çejo juftiçia Regidores caualleros...». El éxplicit (fol. 83v): «...non fean | ofados de faбeo nĵgûn paño legitimo faluo ordido a fefenta $\tau \mid$ dos lenuelos $\tau$ medio». 


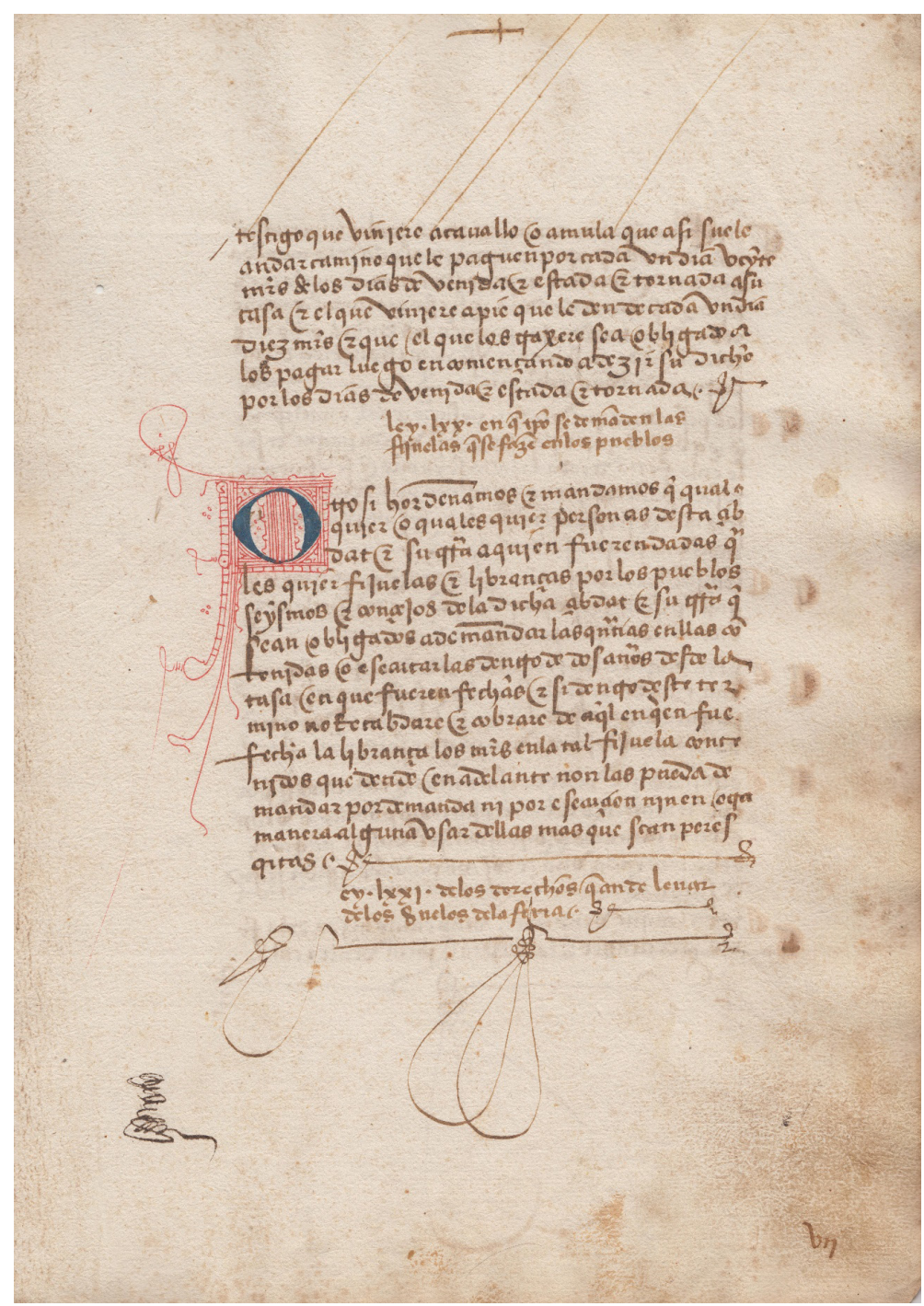

Figura 1. Testimonio $O$, fol. 36r.

En cuanto a los contenidos textuales, los detallamos siguiendo el orden en que aparecen:

- Decisión del concejo de corregir y rehacer las antiguas ordenanzas de Ávila. Nombramiento de una comisión que ha de reunirse en Cardeñosa para tal fin. Día 8 de octubre de 1485 (fols. $1 \mathrm{r}-2 \mathrm{v}$ ). 
- Se nombra a Juan Vázquez Rengifo y a Gil González de Ávila en sustitución de Alonso de Ávila y Gonzalo de Valderrábano para formar parte de la comisión. Se establece como lugar de reunión el monasterio de San Francisco. Tras su discusión y elaboración, se ordena publicar las ordenanzas. Días 10, 12 y 13 de febrero de 1487 (fols. 2v-5v).

- Ordenanzas 63-117 (fols. 30r-78v).

- Correcciones sobre los derechos de los escribanos. Día 23 de febrero de 1488 (fols. 79r-80v).

- Aprobación definitiva de las ordenanzas. Día 23 de febrero de 1488 (fols. 81r-81v).

- Erratas (fol. 82r), con el signo del escribano.

- Ordenanzas aprobadas y añadidas con posterioridad. Son descritas como «las tres hordenanças nuevas» y vienen introducidas por un breve párrafo: "[L]as hordenanças que después de lo susodicho fizieron e hordenaron el conçejo, corregidor, regidores de la dicha çibdad de Ávila, estando ayuntados a su conçejo, a canpana repicada, según que lo an de uso e de costunbre, es lo syguiente». Las tres disposiciones son: ordenanza de los tejeros y olleros, día 20 de marzo de 1490 (fols. 82v-83r); ordenanza sobre la compra de cabritos, día 29 de septiembre de 1490 (fol. 83r-83v); aclaraciones sobre la ordenanza de los paños, ¿1490? (fol. 83v).

- Otras disposiciones (3 h. sueltas): correcciones sobre la ordenanza de los montes, día 8 de octubre de 1510; aranceles de los mesoneros, ¿1510?; nuevos aranceles de los mesoneros y venteros, día 19 de octubre de $1555^{21}$.

Del análisis de nuestro manuscrito se deduce un hecho relevante: nos encontramos, no ante una copia de las Ordenanzas, sino ante el original -desde el punto de vista filológico, referido al códice real, físico- corregido y signado por el escribano:

- Por un lado, materialmente coincide con la descripción que se hace en la aprobación final, donde el escribano Fernán Sánchez de Pareja detalla: «las quales leyes van escriptas en estas ochenta y una hojas deste papel de a pliego entero e en fyn de cada plana señalada de una señal de mi nonbre acostunbrado». En efecto, el texto copiado hasta ese punto, sobre buen papel, llega al folio 81 , y cada plana lleva al final una rúbrica del escribano; además, encontramos la firma de Sánchez de Pareja, con su signo, al fol. 5v (fig. 2), y de nuevo su firma al fol. 82r. Nada de esto encontramos en los otros manuscritos conservados, que sin duda son copias.

21 Recordemos que cada año el concejo aprobaba una gran cantidad de resoluciones, pero muchas de ellas no tenían vocación de permanencia y solo algunas terminaban pasando al corpus normativo. Porras Arboledas, Pedro Andrés. «Las ordenanzas municipales: sus orígenes, contenidos y posibilidades de investigación». Vasconia, 2009, vol. 36, pp. 26-27. 


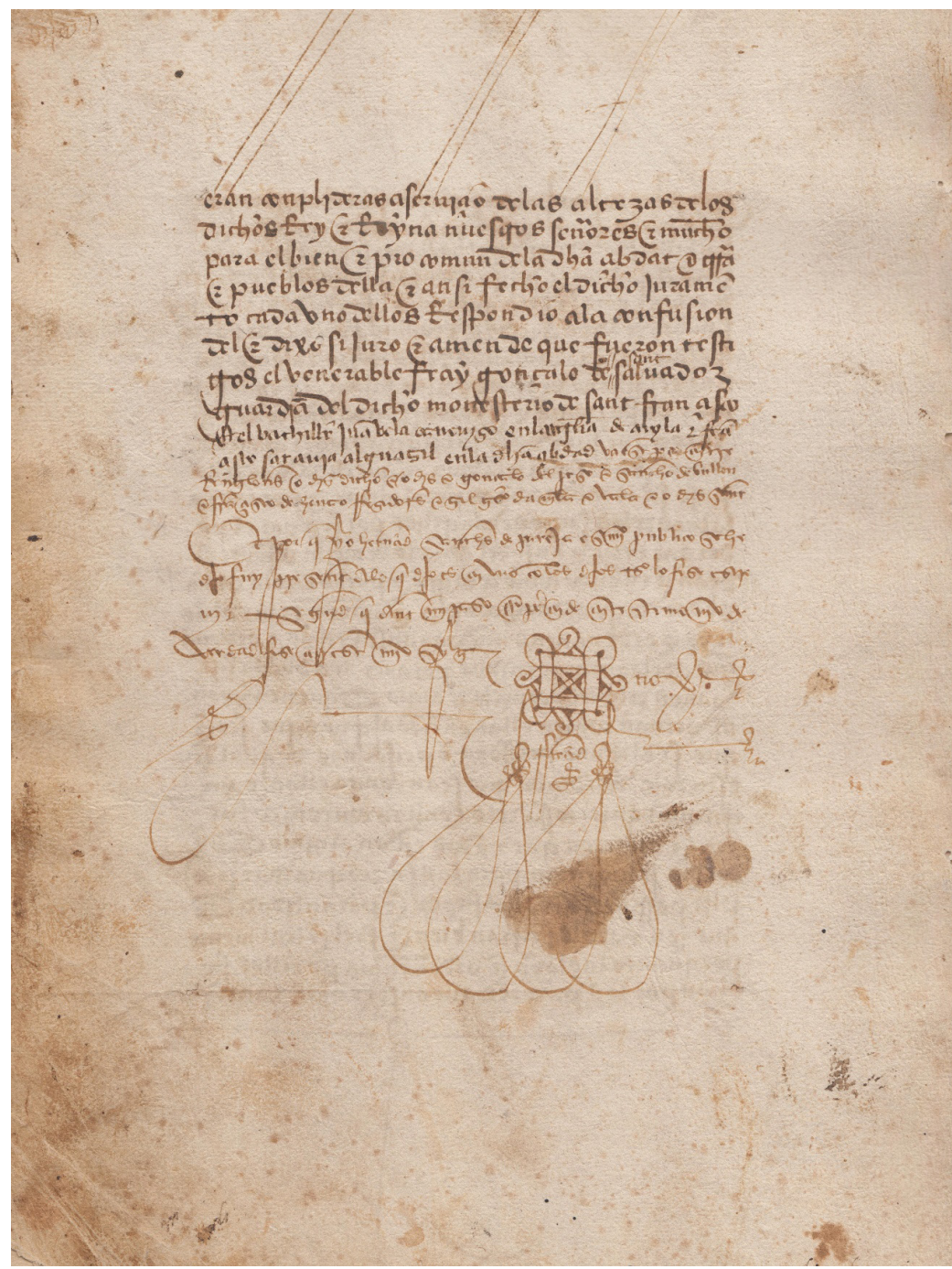

Figura 2. Testimonio $O$, fol. $5 \mathrm{v}$.

- Por otro lado, las erratas descritas en el fol. 82r coinciden puntualmente, a lo largo de todo el códice, con las correcciones hechas «entre renglones» y con el texto que «va escripto sobre raýdo». Esto no sucede, obviamente, en ningún otro manuscrito, ni siquiera en el que contiene el testimonio $A$, donde se copió la misma relación de erratas, detrás de la aprobación, pero estas no se encuentran ya en el lugar correspondiente del texto, pues se copiaba ya corregido. 
Es verosímil suponer que el códice estudiado sea el que tuvo en su poder el escribano de concejo. Recordemos que en Castilla dicho escribano desempeñó una función esencial en la redacción y custodia de los documentos que recogían decisiones del concejo; que desde el reinado de los Reyes Católicos fue prescriptivo conservar aquella documentación, siendo el escribano el responsable de guardar los cuadernos de ordenanzas ${ }^{22}$. Esta obligación de conservarlos se documenta de manera explícita en el siglo xv, por ejemplo, en la ciudad de Orense, pues allí el escribano de concejo debía custodiar las ordenanzas en su propia casa ${ }^{23}$.

\section{Alcance y CONTENido Del MANUSCRito}

Por lo que se ha conservado de los diversos manuscritos de estas Ordenanzas, se puede deducir que el contenido de $O$ hubo de coincidir en lo fundamental con el de $A$, pese a que ambos testimonios se hallan recogidos en códices incompletos. Y aunque $O$ ha sufrido el paso del tiempo como los demás testimonios, con la consiguiente pérdida de contenidos, la buena noticia es que, precisamente, el texto ausente en los otros manuscritos se ha conservado en el nuestro, de modo que se complementan todos ellos y es ya posible recuperar íntegramente las Ordenanzas generales de Ávila de 1487.

Entre las novedades que aporta el testimonio $O$, la más interesante es una serie de contenidos inéditos. En primer lugar, encontramos varias disposiciones que no se conocían en absoluto por haberse perdido o no haber sido incluidas en los manuscritos estudiados hasta ahora (leyes 100,101, 102, 103, 108), las cuales pasamos a comentar brevemente:

- La ley 100 (fols. 54v-55r) regula la compraventa de alcaceres, prohibiendo que se haga "a recatonía», de manera que «los mesmos señores sieguen e manden segar e vender, quier en las alcaçerías, o plaças, o calles públicas de la dicha çibdat».

- En la ley 101 (fol. 55r) se dispone el modo en que deben hacerse las calzadas o empedrado de las calles, estableciendo «que todos los vezinos de la dicha çibdad dentro de los muros adentro della sean obligados de fazer sus calçadas de dos pies en ancho a lo menos» y que esto lo haga "cada uno en toda la pertenençya de su casa». Se establece un plazo para ello de "fasta medio año» desde el momento en que se publiquen las ordenanzas, y la disposición ha de aplicarse a las calles «donde vieren dos regidores, con los mayordomos de conçejo o uno dellos, que se deven fazer». Como se ve, el empedrado debió de iniciarse en la ciudad de Ávila ya durante la década de 1480, aunque todavía diez años después seguía en proceso, por lo que se deduce de ciertas ordenanzas posteriores ${ }^{24}$.

- Resulta interesante el contenido de la ley 102 (fol. 55r-v), por la que se establece que «los basteçedores de las carniçerías christianegas e moriegas e del rastro desta dicha

22 Porras Arboledas, «Las ordenanzas municipales», p. 27.

23 Enjo Babío, Ascensión y Antonio Rubio, M. ${ }^{a}$ Gloria de. «Ordenanzas municipales de Ourense en el siglo Xv: Estudio introductorio». Cuadernos de Estudios Gallegos, 2006, vol. LIII, n. ${ }^{\circ}$ 119, p. 226.

24 Monsalvo Antón, Ordenanzas medievales de Ávila, docs. 41 y 52. 
çibdad non sean enplazados por las rentas e sisas e propios de nuestro conçejo salvo dos días en la semana, que sea el viernes a la terçia e a las bísperas, e el sábado syguiente a la terçia». Además, se fija un emplazamiento diferenciado para los judíos, que no podían asistir los sábados: «e los judíos, los jueves e viernes solamente, e non en otros días». Tengamos presente que a finales del siglo xv la ciudad de Ávila tenía unos mil judíos, junto a aproximadamente 700 mudéjares ${ }^{25}$.

- También reviste especial interés la ley 103 (fol. 55v), referida a la contribución de los hidalgos en las rentas y sisas del concejo. Se dice que «algunas personas, por se llamar fidalgos, se quieren escusar de contribuyr e pagar en las rentas e sisas de nuestro conçejo, seyendo onbres mercadores e tratantes en mercadurías, así de carnes como de pescados e sardinas e azeytes e otros ofiçios ajenos a omes fijosdalgo». En consecuencia, se ordena limitar la exención únicamente a aquellos «fijosdalgo que de su cría tovieren qualesquier cosas para vender e vendieren, o que non lo tenga por ofiçio continuo de conprar para vender e revender», obligándoles a pagar en cualquier otro supuesto. Se añade que «por lo pagar, en esto non se le pare perjuyzio a sus fidalguías o eseçiones e fidalguías, si algunas tovieren». Esta disposición es claro indicio de que quienes estaban exentos, por privilegio de hidalguía, de pagar determinados tributos a menudo se amparaban en tales privilegios para defraudar al concejo, ejerciendo el comercio sin tributar por los productos vendidos a pesar de que nadie debía eludir el pago de impuestos indirectos como las sisas.

- En la ley 108 (fols. 57v-58r) se regula el uso de los soportales de las plazas públicas, estableciendo la siguiente prohibición: «non sean osados de so los portales de las dichas plaças ni de algunas dellas, aunque sean suyos e de sus casas, de poner nin consentir que se pongan ningunas mercadurías nin tratos nin tiendas fuera de las casas e puertas que están cab'ellos, nin los alquileen nin arrienden a otros estraños para que tengan allí tiendas ny tractos». En consecuencia, se ordena que estos soportales queden «esentos para los que pasan e vienen por ellos, e para poner si quisieren sus mercadurías los que vienen a los mercados e trahen provisiones a la çibdad en el tienpo que a ella vienen» y que «a pie e cavalgando puedan pasar por ellos los que quisieren».

Por otro lado, nuestro manuscrito también completa disposiciones que se conocían solo parcialmente:

- La ley 112 (fols. 60v-64r) incorpora antiguas ordenanzas de la ciudad de Ávila sobre administración de justicia, las cuales en $O$ vienen precedidas de un párrafo que ratifica su vigencia «salvo en aquello que es contra las leyes e hordenanças contenidas en este libro e leyes que agora se an fecho por nos el dicho conçejo». Se designa aquí este conjunto de disposiciones como «las leyes e hordenanças que están puestas y asentadas en la tabla, ansí la que está puesta en la yglesia de Sant Juan como en poder de los escrivanos de nuestro conçejo», y se establece que estas deben ser «signadas de los

25 Tapia SÁnchez, Serafín de. «Los mudéjares de la Extremadura castellano-leonesa: notas sobre una minoría dócil (1085-1502)». Studia Historica. Historia Medieval, 1989, vol. 7, p. 124; Tapia SÁnchez, Serafín de. «Los judíos de Ávila en vísperas de la expulsión». Sefarad, 1997, vol. 57, n. ${ }^{\circ}$ 1, p. 143. 
escrivanos de nuestro conçejo». A continuación, se copia literalmente el contenido tal como se recogió en un documento de mediados del siglo $\mathrm{xv}^{26}$. En el testimonio $A$, por pérdida del fol. 62 , no se conservan ni el título ni el párrafo introductorio, aunque Monsalvo supuso acertadamente, a la vista de lo conservado, que «es la ley 112, o parte de ella ${ }^{27}$.

- En cuanto a la ley 115, es la única que plantea alguna duda a la hora de dar por restituido plenamente su contenido, sobre todo porque no se ha conservado íntegramente en ninguno de los testimonios. En $A$ apenas tenemos algunas líneas del final (fol. 78r); en $B$ aparentemente el contenido está completo (fol. 45r-v), pero no el epígrafe o título que lo introduce; en $O$, finalmente, aunque no se conserva el desarrollo dispositivo, sí se recoge, precisamente, el título, al final del fol. 76v: "Cómo se an de guardar estas leyes, e que se juren por las justiçias al tienpo de su reçebimiento, e cómo revocaron las hordenanças viejas e se mandaron pregonar estas leyes». Monsalvo, que tan solo pudo estudiar $A, B$ y $C$, expresaba sus dudas acerca de cuál podría ser el contenido de esta ley, la cual suponía no muy amplia, «de medio folio o menos, a tenor de la reducida laguna documental»-falta el folio 77 en el testimonio $A$-, pero con acertada intuición supo identificar esta ordenanza en uno de los párrafos de $B$, ubicado tras la disposición «sobre los tyros de la pólvora», en el fol. 45r-v. Matizaba, no obstante, que el orden diferente que presenta $B$ le impedía asegurarlo de modo fehaciente ${ }^{28}$. Felizmente, hoy podemos ya constatar, a la vista de nuestro manuscrito, que el título de la ley 115 se corresponde con el contenido de ese párrafo.

Además de estas novedades, nuestro manuscrito contiene muchas de las disposiciones que hasta hoy solo se conocían a través del testimonio $B$, donde no fueron numeradas y se recogieron en otro orden. Por lo tanto, contamos ahora con una valiosa información al poder asignarles una ubicación en el ordenamiento original de 1487. Estas leyes son las siguientes: 92, 93, 94, 95, 96, 97, 98, 99, 104, 105, 106, 107, 109-110, 111. Para que puedan ser analizadas más cómodamente las equivalencias y los cambios de orden que existen entre los testimonios, insertamos como anexo una tabla con todas las disposiciones, indicando el orden que presentan en cada caso.

También descubrimos, al cotejar $O$ con los otros testimonios conservados, algunas variantes que, aunque escasas, contribuyen a fijar el texto. Valga como ejemplo el siguiente pasaje de la ley 80 :

$[O]$... los fieles de la dicha çibdat ni el alguazil de la cibdat non se entremetan en manera alguna a prendar a los judíos e moros en sus juderías e morerías de los sitios adentro, aunque labren e fagan sus lavores a puertas abiertas los días de las pascuas e domingos e fiestas que son de guardar ni en otros algunos, ni los tomen vestidos algunos dentro de las dichas morerías e juderías aunque dentro en ellas anden sin seńales.

26 Archivo Municipal de Ávila, Hist. 1/182.

27 Monsalvo Antón, Ordenanzas medievales de Ávila, p. 136.

28 Monsalvo Antón, Ordenanzas medievales de Ávila, p. 151. 
$[B]$... los fieles de la dicha cibdat non se entremetan en manera alguna a prender a los judíos e moros en sus juderýas e morerýas de los sitios adentro, aunque labren e fagan sus lavores a puertas abiertas los días de las pasquas e domyngos e fiestas que son de guardar, ni en otros algunos dentro de las dichas morerýas e juderías, aunque dentro dellas anden syn señales.

\section{Pautas para una edición de las Ordenanzas generales de i 487}

A la vista de los contenidos que ofrece $O$, desconocidos hasta ahora, podemos ya plantear la conveniencia de una edición que recoja íntegro el texto de las Ordenanzas generales con la certeza de aproximarnos en gran medida al original tal como fue aprobado el 16 de marzo de 1487 -un texto ideal $\Omega$-. Para esta edición, que esperamos poder ofrecer en breve, convendrá tener en cuenta algunos aspectos que pasamos a comentar.

Monsalvo habló de «dos versiones o libros de ordenanzas» ${ }^{29}$, pero sin poder explicar por qué ambas presentan una estructura distinta. En efecto, puede decirse que hay una versión extensa, de 117 disposiciones, que hoy se conserva fragmentariamente, aunque de forma complementaria, en los testimonios $O$ y $A$, y que sin duda era la recogida en el manuscrito estudiado por Martín Carramolino $(D)$, cuyos títulos o epígrafes coinciden, en el mismo orden, con los de $O$ y $A$. Hay otra versión breve, de la que se conocen dos copias incompletas -testimonios $B$ y $C$ - que contienen únicamente 69 de esas disposiciones y en un orden diferente.

La razón por la que esta versión breve presenta un orden distinto no es en absoluto evidente. Corral, que solo la conoció a través del testimonio $C$, defendió que estaba inspirada en la versión extensa, pero que se trataba de un texto refundido en el que fueron excluidas determinadas disposiciones ${ }^{30}$. Hoy sabemos, a la vista del testimonio $B$, que en gran medida es un texto incompleto por la pérdida de bastantes folios. En consecuencia, no parece que puedan extraerse conclusiones categóricas, pues se trata de una laguna demasiado amplia y no es posible saber qué ordenanzas se perdieron y cuáles son las que no fueron incluidas inicialmente.

Por su parte, Ajo González ${ }^{31}$ defendió que la versión breve sería en realidad un borrador elaborado por la comisión reunida en Cardeñosa en 1485, proyecto desechado, a su juicio, porque no satisfizo a los procuradores de la tierra y sus sexmos. Respecto a aquel hipotético borrador, aseguraba: «para mí no hay duda de ser éste el ejemplar que existe en el archivo municipal»-se refería al testimonio $B$-; pero no daba argumentos que apoyasen tal afirmación. De hecho, contradicen esa hipótesis varios detalles:

- El manuscrito no tiene el aspecto de un borrador, sino de una copia que, como suponía Monsalvo, trasladó a limpio un texto contenido en otro documento; apenas encontramos correcciones, tachaduras ni ańadidos entre renglones, como habría

29 Monsalvo Antón, Ordenanzas medievales de Ávila, p. 12.

30 Corral García, «Algunas manifestaciones», pp. 53-54.

31 Ajo González de Rapariegos, Historia de Avila y de toda su tierra, pp. 182 y 195. 
sido de esperar en un borrador. Por el contrario, la caligrafía es cuidada y se añadió decoración en las iniciales.

- Si bien las disposiciones presentan un orden diferente, no hay sin embargo grandes cambios en cuanto a su contenido textual, más allá de simples variantes gráficas o lingüísticas.

- $\quad$ Esta copia recogió, a un tiempo, el texto del 8 de octubre de 1485 y los preliminares fechados entre el 10 y el 13 de febrero de 1487, además de las disposiciones añadidas entre 1488 y 1490 . No cabe duda de que el manuscrito fue elaborado con posterioridad a 1490, y no tendría sentido que se copiara entonces el texto de un hipotético proyecto anterior a la aprobación de las Ordenanzas, desechado o incompleto.

Por lo tanto, cabe suponer que la versión breve se concibió como una selección de disposiciones hecha, con posterioridad, sobre el texto de la versión extensa, de 1487. Su elaboración podría relacionarse, de modo verosímil, con algún uso específico, recogiéndose únicamente aquellas ordenanzas que eran del interés o utilidad de quien encargó esta copia. Quizá resulte significativo que el traslado contenido en el testimonio $C$ lo mandase hacer el procurador síndico general del común, quien tenía en su poder el viejo manuscrito $B$, un libro de ordenanzas que tal vez había sido durante siglos el ejemplar usado por el procurador o síndico personero de Ávila, pero que ya en el xvıII resultaba de difícil lectura ${ }^{32}$. Aunque parece menos probable, tampoco hay que descartar la posibilidad de que esta versión respondiera a un encargo particular ${ }^{33}$. Aún quedaría por aclarar el motivo de la alteración en el orden de las leyes, pero quizá un estudio detenido, a la vista de las equivalencias recogidas en el anexo, pueda contribuir a despejar esta duda en un futuro.

Podemos concluir, pues, que del original -testimonio $O$ - proceden directa o indirectamente los demás testimonios: $A$ es una copia fiel, muy cuidada, con pocas variantes y escasos errores; $B$ recoge solo parcialmente el texto original e introduce importantes cambios en la ordenación de los contenidos; $C$ es una copia de $B$ que apenas introduce variantes gráficas y algunas variantes de lengua irrelevantes.

A la vista de estos datos, podemos trazar ya un plan de edición de las Ordenanzas generales de Ávila:

- Se editará el conjunto de documentos que pueden considerarse parte de aquel proyecto normativo: los preliminares de 1485-1487, las 117 disposiciones, la rectificación de los derechos de los escribanos y la aprobación definitiva del 23 de febrero de 1488 .

32 A continuación del texto de las Ordenanzas, encontramos en $C$ la siguiente aclaración: «Es copia bien y fielmente sacada de las ordenanzas antiguas forradas en tabla que, para efecto de traduzirlas a letra legible de la que hoi se usa, don Pedro Galán de Morales, procurador síndico general del común de esta ciudad de Ávila por ambos estados, me entregó a mí el infrascripto escribano del número de esta dicha ciudad y su tierra...".

33 Sirva como precedente el caso de Pedro Rodríguez, vecino de Ávila, que en 1392 presentó un cuaderno de ordenanzas ante el alcalde Pedro Álvarez y solicitó un traslado del mismo, explicando que le era de utilidad "para guarda de sus heredades». Monsalvo Antón, Ordenanzas medievales de Ávila, pp. 37-38. 
- Se tomará como texto base el testimonio $O$, por ser el original, y aquellas lagunas textuales producidas por pérdida de folios se suplirán con $A, B$ y $C$.

- En aparato crítico quedarán recogidas las posibles enmiendas al texto, junto con la lección original, para lo cual tendremos a la vista todos los testimonios.

\section{ANEXo: CORRESPONDENCIAS ENTRE LOS DisTintos TESTIMONIOS}

Los números remiten a las leyes u ordenanzas en cada uno de los testimonios principales. Hemos marcado con asterisco $\left(^{*}\right)$ aquellas disposiciones que están incompletas. En el caso del testimonio $B$, donde no fueron numeradas las ordenanzas, ańadimos nosotros entre [ ] el número correspondiente según el orden en que aparecen recogidas.

\begin{tabular}{|c|c|c|c|c|c|}
\hline$O$ & $A$ & $B$ & $O$ & $A$ & $B$ \\
\hline & 2 & [2] & & 61 & \\
\hline & 3 & [3] & & 62 & {$[40]$} \\
\hline & 4 & [4] & 63 & 63 & \\
\hline & 5 & [5] & $* 64$ & 64 & \\
\hline & 6 & [6] & $* 65$ & 65 & \\
\hline & 7 & [18] & 66 & 66 & \\
\hline & 8 & [7] & 67 & 67 & \\
\hline & 9 & [8] & 68 & 68 & \\
\hline & 10 & [9] & 69 & 69 & \\
\hline & 11 & [10] & 70 & 70 & \\
\hline & 12 & [15] & 71 & 71 & [39] \\
\hline & 13 & {$[35],[36]$} & 72 & 72 & \\
\hline & 14 & [11] & 73 & 73 & \\
\hline & 15 & [13] & 74 & 74 & \\
\hline & 16 & [14] & 75 & 75 & \\
\hline & 17 & [16] & 76 & 76 & {$[41]$} \\
\hline & 18 & [17] & 77 & 77 & \\
\hline & 19 & [29] & 78 & 78 & \\
\hline & 20 & [12] & 79 & 79 & \\
\hline & 21 & [34] & 80 & 80 & \\
\hline & 22 & & 81 & 81 & {$[63]$} \\
\hline & 23 & [37] & 82 & 82 & {$[64]$} \\
\hline & 24 & [19] & 83 & 83 & \\
\hline & 25 & [22] & 84 & 84 & \\
\hline & 26 & [24] & 85 & 85 & {$[65]$} \\
\hline & 27 & [23] & 86 & 86 & {$[45$} \\
\hline & 28 & [20] & 87 & 87 & {$[46$} \\
\hline & 29 & [21] & 88 & 88 & {$[47]$} \\
\hline & 30 & [25] & 89 & 89 & [38. \\
\hline & 31 & [26] & 90 & 90 & {$[48]$} \\
\hline & 32 & {$[27]$} & 91 & 91 & {$[49]$} \\
\hline & 33 & [28] & 92 & & [51] \\
\hline & 34 & & 93 & & {$[52]$} \\
\hline & 35 & [30] & 94 & & {$[53$} \\
\hline
\end{tabular}


LAS ORDENANZAS GENERALES DE ÁVILA DE 1487. EL CÓDICE ORIGINAL.

\begin{tabular}{|l|l|l|}
\hline$O$ & $A$ & $B$ \\
\hline & 36 & \\
\hline & 37 & {$[31]$} \\
\hline & 38 & {$[32]$} \\
\hline & 39 & {$[33]$} \\
\hline & 40 & \\
\hline & 41 & {$[50]$} \\
\hline & 42 & \\
\hline & 43 & \\
\hline & 44 & \\
\hline & 45 & \\
\hline & 46 & \\
\hline & 47 & \\
\hline & 48 & \\
\hline & 49 & \\
\hline & 50 & \\
\hline & 51 & \\
\hline & 52 & \\
\hline & 53 & \\
\hline & 54 & \\
\hline & 55 & \\
\hline & 56 & \\
\hline & 57 & \\
\hline & 58 & \\
\hline & 59 & \\
\hline & 60 & \\
\hline & & \\
\hline
\end{tabular}

\begin{tabular}{|c|c|c|}
\hline$O$ & $A$ & $B$ \\
\hline 95 & & {$[54]$} \\
\hline 96 & & {$[55]$} \\
\hline 97 & & {$[56]$} \\
\hline 98 & & {$[57]$} \\
\hline 99 & & {$[62]$} \\
\hline 100 & & \\
\hline 101 & & \\
\hline 102 & & \\
\hline 103 & & \\
\hline 104 & & {$[58]$} \\
\hline 105 & & {$[59]$} \\
\hline 106 & & {$[43]$} \\
\hline 107 & & {$[66]$} \\
\hline 108 & & \\
\hline 109 & & {$[60]$} \\
\hline 110 & & {$[61]$} \\
\hline 111 & & \\
\hline 112 & ${ }^{*} 112$ & \\
\hline 113 & 113 & \\
\hline 114 & ${ }^{*} 114$ & {$[42]$} \\
\hline${ }^{*} 115$ & ${ }^{*} 115$ & $*[67]$ \\
\hline$* 116$ & 116 & {$[68]$} \\
\hline 117 & 117 & {$[69]$} \\
\hline & & \\
\hline & & \\
\hline & & \\
\hline
\end{tabular}

\section{6}

\section{REFERENCIAS BIBLIOGRÁFICAS}

Ajo González de Rapariegos, Cándido M. ${ }^{a}$. Historia de Ávila y de toda su tierra, de sus hombres y sus instituciones, por toda su geografía provincial y diocesana. Tomo XII. Ávila: Institución Alfonso de Madrigal, el Tostado-Centro de Estudios e Investigaciones Ascético-místicos, Histórico-bíblicos y Literarios, 1994.

Álvarez Álvvarez, César. «Los archivos municipales: fuentes básicas para el estudio de los derechos locales en la Corona de Castilla». Revista de Historia Jerónimo Zurita, 2004, vol. 78-79, pp. 49-68.

Belmonte Díaz, José. La ciudad de Ávila. Estudio histórico. Ávila: Caja de Ahorros de Ávila, 1987.

Corral García, Esteban. "Algunas manifestaciones de la potestad de ordenanza en Castilla y León». Boletín de la Institución Fernán González, 1984, vol. 202, pp. 35-70.

Corral García, Esteban. Ordenanzas de los concejos castellanos: formación, contenido y manifestaciones (s. XIII-XVIII). Burgos: E. Corral, 1988.

Enjo Babío, Ascensión y Antonio Rubio, M. ${ }^{a}$ Gloria de. «Ordenanzas municipales de Ourense en el siglo Xv: Estudio introductorio». Cuadernos de Estudios Gallegos, 2006, vol. LIII, n. ${ }^{\circ}$ 119, pp. 209-228.

Foronda, Marqués de. "Las ordenanzas de Ávila». Boletín de la Real Academia de la Historia, 1917-1918, vol. 71, pp. 381-425 y 463-520; vol. 72, pp. 25-47, 225-254 y 310-326. 
Foronda, Marqués de. Las ordenanzas de Ávila (manuscrito de 1485 y su copia, en acta notarial, de 1771) publicadas en el 'Boletín de la Real Academia de la Historia'. Madrid: Real Academia de la Historia, 1918.

Gautier Dalché, Jean. «Les processus de décision dans un gouvernement urbain selon les Ordonnances d'Âvila (1487)». En la España Medieval, 1985, vol. 6, pp. 507-520.

Ladero Quesada, Manuel F. Las ciudades de la Corona de Castilla en la Baja Edad Media (siglos XIII al XV). Madrid: Arco Libros, 1996.

Ladero Quesada, Miguel Ángel. «Las ordenanzas locales. Siglos XiII-XviII». En la España Medieval, 1998, vol. 21, pp. 293-337.

Ladero Quesada, Miguel Ángel y Galán Parra, Isabel. «Las ordenanzas locales en la Corona de Castilla como fuente histórica y tema de investigación (siglos XIII al XVIII)». Anales de la Universidad de Alicante. Historia Medieval, 1982, vol. 1, pp. 221-243.

Martín Carramolino, Juan. Historia de Avila, su provincia y obispado. 3 vols. Madrid: Librería Española, 1873.

Monsalvo Antón, José María. Ordenanzas medievales de Avila y su Tierra. Ávila: Institución Gran Duque de Alba, 1990.

Monsalvo Antón, José María. «Gobierno municipal, poderes urbanos y toma de decisiones en los concejos castellanos bajomedievales (consideraciones a partir de concejos salmantinos y abulenses)». En Las sociedades urbanas en la España medieval: XXIX Semana de Estudios Medievales. Estella: Gobierno de Navarra, 2003, pp. 409-488.

Olmos Herguedas, Emilio. «Les ordonnances municipales dans la Couronne de Castille au Bas Moyen Âge». European Review of History-Revue Européenne d'Historie, 1994, vol. 1, n.o 1, pp. 101-104.

Olmos Herguedas, Emilio. «El poder urbano y sus estrategias para influir sobre el territorio. Aproximación metodológica desde las ordenanzas concejiles castellanas». En ArízaGA Bolumburu, Beatriz y Solórzano Telechea, Jesús Ángel (eds.). La ciudad medieval y su influencia territorial. Logroño: Instituto de Estudios Riojanos, 2007, pp. 493-517.

Porras Arboledas, Pedro Andrés. «Las ordenanzas municipales. Algunas propuestas para su estudio y un ejemplo». Espacio, Tiempo y Forma. Serie III, Historia Medieval, 1994, vol. 7, pp. 49-64.

Porras Arboledas, Pedro A. «La práctica de la policía en Castilla a través de los fueros, ordenanzas y bandos de buen gobierno durante los siglos xiII al xvi». En Cauchies, Jean-Marie y Bousmar, Éric (dirs.). «Faire bans, edictz et statuz»: Légiférer dans la ville médiévale. Sources, objets et acteurs de l'activité législative communale en Occident, ca. 1200-1500. Actes du colloque international tenu à Bruxelles les 17-20 novembre 1999. Bruxelles: Publications des Facultés Universitaires Saint-Louis, 2001, pp. 577-586.

Porras Arboledas, Pedro Andrés. «Las ordenanzas municipales: sus orígenes, contenidos y posibilidades de investigación». Vasconia, 2009, vol. 36, pp. 19-35.

TApia SÁnchez, Serafín de. "Los mudéjares de la Extremadura castellano-leonesa: notas sobre una minoría dócil (1085-1502)». Studia Historica. Historia Medieval, 1989, vol. 7, pp. 95-126.

TApia SÁnchez, Serafín de. "Los judíos de Ávila en vísperas de la expulsión». Sefarad, 1997, vol. 57, n. ${ }^{\circ} 1$, pp. 135-178. 